\title{
How do Concept-Maps Function for Reading Comprehension Improvement of Iranian Advanced EFL Learners of Both Genders?
}

\author{
Mohammad Saber Khaghaninejad ${ }^{1} \&$ Mansour Arefinejad ${ }^{2}$ \\ ${ }^{1}$ Department of Foreign Languages and Linguistics, Shiraz University, Iran \\ ${ }^{2}$ English Department, Persian Gulf University of Boushehr, Boushehr, Iran \\ Correspondence: Mohammad Saber Khaghaninejad, Department of Foreign Languages and Linguistics, Shiraz \\ University, Iran. Tel: 98-713-613-4511. Email: mskhaghani@shirazu.ac.ir
}

\author{
Received: April 10, 2015 Accepted: May 13, 2015 Online Published: June 29, 2015 \\ doi:10.5539/elt.v8n7p174 URL: http://dx.doi.org/10.5539/elt.v8n7p174
}

\begin{abstract}
This study was an attempt to examine the effect of concept mapping on reading comprehension of Iranian EFL learners. Pretest-posttest design was employed to scrutinize the possible improvement of the study's participants who were male and female learners whose ages ranged from 19 to 40 and had taken general English courses at Islamic Azad University of Kharg. Two groups (one experimental and one control group) were exposed to the same reading comprehension test as the pre-and post-test, however, only the experimental group received the special treatment of concept mapping techniques for different texts during the treatment. After the application of the study's treatment, data analysis procedure initiated which indicated that experimental group who received explicit concept mapping instruction had a better performance than the control group on the final reading comprehension test. In addition, the findings shows that students who used this strategy during the seven-week treatment had better results on comprehension reading test and could understand the reading passages better. The findings imply that concept maps can positively affect the reading comprehension ability of Iranian advanced EFL learners. It was also revealed that female learners were superior at employing concept-maps in comparison with their male peers.
\end{abstract}

Keywords: reading comprehension improvement, concept-mapping technique, gender-dependent differences of using concept-maps

\section{Introduction}

The importance of reading becomes yet more recognizable when it comes to reading in a second or foreign language and for academic purposes or in an academic context (Day \& Bamford, 2002; Eskey, 2005; Grabe, 2004). In spite of the importance and complexity of reading, it is sometimes erroneously viewed just as a passive process of reconstructing the author's intended meaning that is transmitted through language (Nunan, 2000). Rejecting such a perspective toward reading as a single skill that relies on a unitary cognitive process, current views of reading development hold it as a progressive attached sequence of variables that moves from the visual symbol recognition to the text comprehension (e.g., Khodadady \& Khaghaninejad, 2012; Kremer, 2005). Concept maps include concepts, usually enclosed in circles or boxes of some type, and relationships between concepts indicated by a connecting line linking two concepts. Words on the line referred to as linking words or linking phrases, specify the relationship between the two concepts.

One of the characteristics of concept maps is that they tend to be read progressing from the top downward. According to this characteristic, hierarchical concept maps are created which present more general and more inclusive concepts at top of map and more concrete and more specific concepts at the bottom (Gul \& Boman, 2006). Moreover, representing knowledge in this way allows one to gain an overview of a domain of knowledge because nodes contain keywords and short sentences and the reader can develop a holistic understanding of the topic quickly. Feeling the same need and interest, this study endeavored to investigate the effect of using concept maps in the reading comprehension process of EFL learners. The results of this study may shed light on the effectiveness of this particular strategy on EFL students' reading proficiency and might provide insights for possible differences this strategy brings about for male and female Iranian English learners. The study has been an attempt to answer the following research questions: 
- Does concept-mapping have any effect on the reading comprehension improvement of advanced Iranian English learners?

- Does concept-mapping have similar effects for both male and female advanced Iranian English learners?

\section{Background}

The efficacy of instructional schemata or images at any of language skills have been studied and documented (e.g., Khodadady \& Khaghaninejad, 2012; Berkowitz, 1986; Rivard \& Yore, 1992). This may justify the necessity of similar attempts to illuminate the positive function of schematic instructional materials for teaching reading passages as the most needed language skill for students, in particular. Concept maps in a very simplified definition are "pictorial presentation of the texts' contents" (Snow, 2002, p. 34). These meaning organizers can play an unbelievable role in the texts' comprehension and can assist meaningful learning at any pedagogical program.

What can be extracted from the Ausible's (1968) meaningful learning is the type of organized learning in which the existing knowledge should be joined to the upcoming knowledge; Concept maps embody meaningful learning in the best way possible in that they organize the new knowledge in the systematized way ready to enter the working memory (Miller, 2006). Burdumy (2006) and Zmach et al. (2007) tried to explore and introduce the most promising reading comprehension strategies and explicated the positive influence and undeniable role of graphic representations in EFL/ESL learning process.

Since the mid-1970, close attention has been given to the role of strategies in L2 learning (e.g., Oxford, 2002). Strategies are those specific "attacks" that are employed for a given problem, and that vary considerably within each individual (Brown, 2007). They are the moment-by-moment techniques that are employed to solve "problems" posed by second language input and output. Chamot (2005) defined strategies quite broadly as "procedures that facilitate a learning task, strategies are most often conscious and goal-driven" (p. 112). Concept maps as one of the main strategies employed in pedagogic contexts were first introduced by Novak's research dealing with the quality of children's learning process in 1972 (Novak \& Musonda, 1991). Interviewing children, he came up with the necessity of finding a more promising way to represent children's conceptual knowledge in the form of a concept maps.

Graphic organizers are recommended as a technique in reading tasks by Chularut and De Backer (2003) because they provide schematic scaffolds that encourage students to extract and represent the meaning of words from texts. Concept mapping as a meta-cognitive and graphic organizer strategy, which emphasizes organization may help students to improve their reading proficiency (Chularut \& De Backer, 2003). Since the importance of reading comprehension for EFL learners has generally been proved, the interest of language teachers, educators, and material developers toward the notion is steadily on the increase. Success in such a complex process requires investigation regarding so many factors that might contribute to or correlate with the reading comprehension.

To Fahim and Samadian (2011), teacher is in an ideal position to aid students become more comfortable with learning approaches they have not previously experienced. Teachers at higher levels are particularly freer in their approach to augment the quality of their instructions through variety of ways such as application of concept-maps for comprehension tasks. Fahim and Samadian (ibid.) also believed that leading students are aware of their strengths and weaknesses which results in their prosperity in instructional context. In the same vein, Liu, Chen, and Chang (2010) investigated the effectiveness of the concept mapping learning strategy on learners' English reading comprehension skill. The result of the study indicated that the concept mapping learning strategy was more effective for the low-level learners than for the high-level group, in terms of their performance on reading comprehension skill.

\section{Method}

\subsection{Participants}

Participants of the study consisted of 80 students of Industrial Management at Islamic Azad University of Kharg Island who took general English as one of their semester's courses. They were male and female advanced EFL learners whose ages ranged from 19 to 40, and were selected randomly and classified into two groups of control (who underwent the traditional method of reading comprehension translating the text and vocabulary memorization) and experimental (who experienced concept-mapping as a technique for comprehending the same reading passages). Then, in order to investigate the possible relationship between gender and reading comprehension improvement via concept maps, experimental participants were categorized into two categories of males and females. During the semester, 17 sessions were held and every session lasted for one hour and half. 


\subsection{Instrumentations}

The course book which is used for this study is concepts and comments by Ackert (1999) which is designed to teach reading skills of comprehension, finding the main idea, making inferences, and using context clues and suffixes to learn new words. The employed tests were also the tests which were put at the end of each reading passage; these multiple-choice test items were used to construct the pre and the post-test of the enquiry. In addition, some hands-outs were employed to clarify the application of concept-maps in reading comprehension classes. The following are two instances; in the first students were required to fill in the blanks and in the second they observed the hierarchy of the proposed concepts in the text.

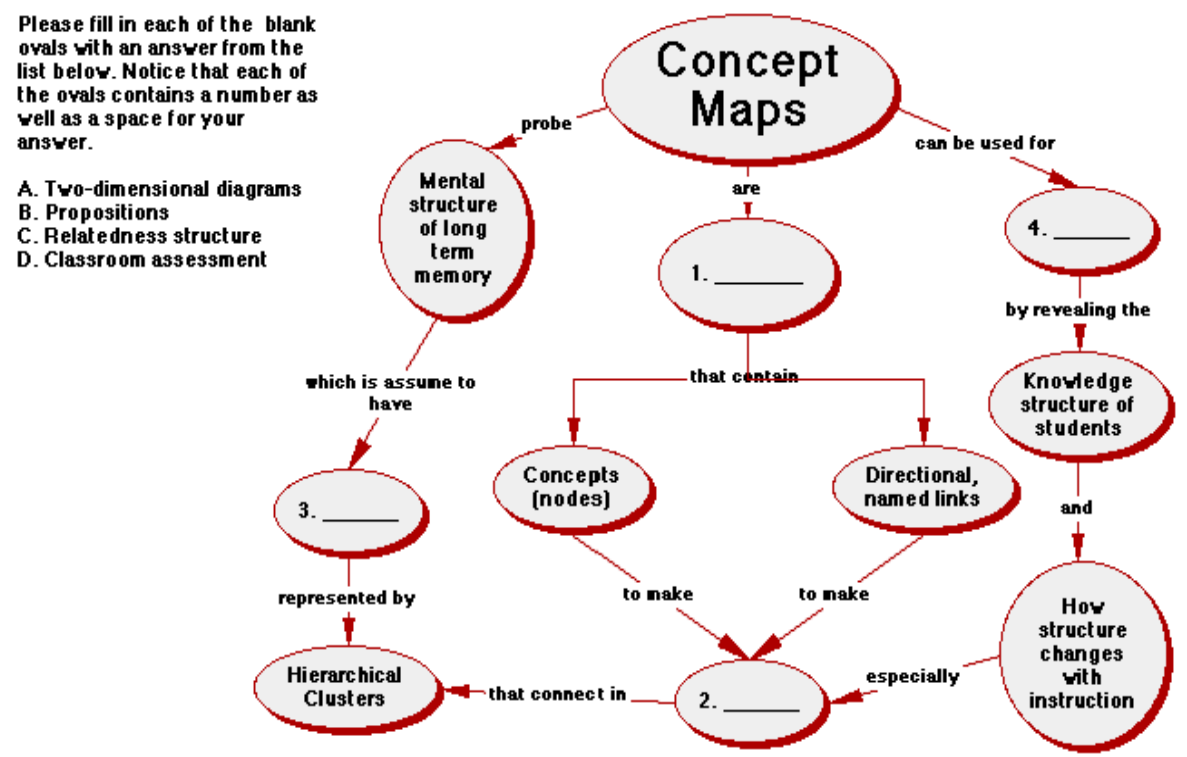

Figure 1. An example of "Fill in the map model"

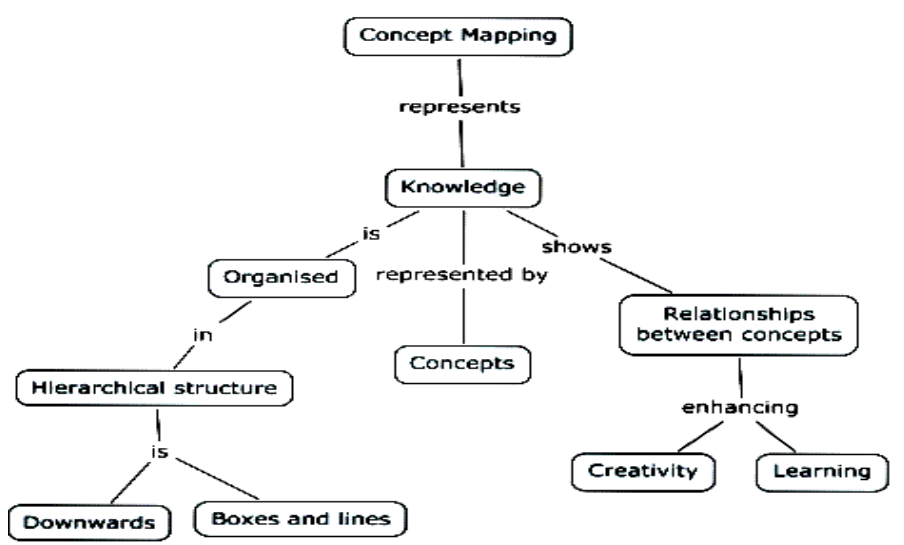

Figure 2. An example of "Hierarchical map model"

\subsection{Procedure}

For gaining certitude that all the participants have been at the same level of reading comprehension ability, a pre-test was conducted. Then, the participants were classified into two main classes of control and experimental groups as the main groups of the study and then the experimental participants were categorized into two categories of males and females. Control participants were taught the texts traditionally employing translations and attempts to find mother-tongue equivalents for English unfamiliar words while the experimental participants were familiarized with concept maps and their applications for understanding the reading passages explicitly. Concept maps are schematic instruments employed for categorizing information in a pictorial form through 
drawing. To begin the actual study, experimental participants were asked to read short scientific articles as their regular class activities and consequently, spent two 35-min class periods individually mapping 20 pre-selected terms from the article in their concept-map template. The mapping strategy use lasted 12 days. The following table depicts the performed class activities of the two groups.

Table 1. Class activities for the experimental and the control participants

\begin{tabular}{|c|c|c|c|}
\hline Experimental participants & & Control participants & \\
\hline Activity & Min. & Activity & Min. \\
\hline Reading the text & 20 & Reading the text & 20 \\
\hline Practicing how to concept-map the text & 15 & Translating the text sentence by sentence & 40 \\
\hline Actual concept-mapping & 35 & Answering the reading comprehension questions & 10 \\
\hline $\begin{array}{l}\text { Answering the reading comprehension } \\
\text { questions based on concept-maps }\end{array}$ & 10 & $\begin{array}{l}\text { Summarizing the text and reviewing the new } \\
\text { vocabulary }\end{array}$ & 20 \\
\hline Summarizing the text based on concept-maps & 10 & & \\
\hline
\end{tabular}

\section{Results and Discussion}

\subsection{Results}

This study investigated the effect of concept mapping on reading comprehension of Iranian EFL learners of both genders. In order to answer the research questions, one experimental and one control group were formed and then experimental participants were divided into two classes of males and females. A pre-test was administered for all the participants to see if they had been at the same level of reading comprehension ability. Scoring the reading comprehension pre-test, it was shown that the average-point of the experimental participants was 14.77 while the average-point for the control participants was 14. 84. Employing an independent-samples t-test, it was found that this mean-difference was not statistically significant and the control and the experimental participants have performed similarly on the study's pre-test (Sig. $=0.513>0.05)$.

Table 2. Mean comparison of the control and the experimental participants on the pre-test

\begin{tabular}{lllllll}
\hline Levene's Test for Equality of Variances & \multicolumn{6}{l}{ t-test for Equality of Means } \\
\hline & $\mathrm{F}$ & $\mathrm{t}$ & $\mathrm{df}$ & Sig. (2-tailed) & Mean Difference & Std. Error D. \\
\hline Equal var. assumed & 4.045 & -.662 & 78 & .513 & -.08000 & .120 \\
Equal var. not assumed & & & & 24.109 & .514 & -.080 \\
\hline
\end{tabular}

After the pre-test, the experimental group received a seven-week special concept mapping instruction. Meanwhile, the control group continued its regular class's activities offered by the course book. After seven weeks, all groups were taken a parallel post-test which was administered to examine the possible improvement of the experimental participants at the end of seven-week instruction. Scoring the reading comprehension post-test, it was revealed that the average-point of the experimental participants was 16.80 while the average-point for the control participants was 15.71. Using a second independent-samples t-test, it was revealed that the experimental participants have outperformed in comparison to their peers in the control group (Sig. $=.007<0.05$ ).

Table 3. Mean comparison of the control and the experimental participants on the post-test

\begin{tabular}{lllllll}
\hline Levene's Test for Equality of Variances & \multicolumn{5}{l}{ t-test for Equality of Means } \\
\hline & $\mathrm{F}$ & $\mathrm{t}$ & $\mathrm{df}$ & Sig. (2-tailed) & Mean Difference & Std. Error D. \\
\hline Equal var. assumed & 11.676 & 2.921 & 78 & .007 & .90667 & .3103 \\
Equal var. not assumed & & & & .009 & .90667 & .3125 \\
\hline
\end{tabular}


Figure 3 depicts the performances of the control and the experimental participants on the both reading comprehension pre and post-test. As discernible, participants of both groups have had better performances on the post-test than the pre-test but the degree of this betterment was more notable for the experimental.

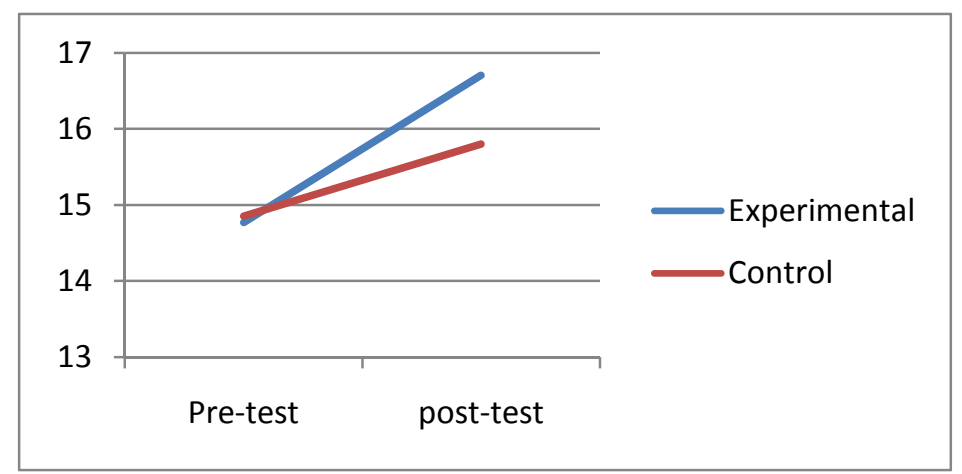

Figure 3. Participants' performances on the reading comprehension pre and post-test

For answering the second research question and to explore the possible effect of gender on the quality of utilizing concept-maps, the performances of the male and the female experimental participants have been compared. A third independent samples-t-test was employed to check this difference statistically. As Table 4 presents, male and female experimental participants have had statistically different performances (Sig. $=0.03<$ 0.05). The female average-point on the post-test was 16.93 while it was 16.41 for their male peers. Figure 4 illustrates the performances of the experimental male and female participants on the study's pre and post-test.

Table 4. Mean comparison of male and female experimental participants on the post-test

\begin{tabular}{lllllll}
\hline Levene's Test for Equality of Variances & \multicolumn{6}{l}{ t-test for Equality of Means } \\
\hline & $\mathrm{F}$ & $\mathrm{t}$ & $\mathrm{df}$ & Sig. (2-tailed) & Mean Difference & Std. Error D. \\
\hline Equal var. assumed & 8.476 & 4.971 & 38 & .03 & 1.003 & .3409 \\
Equal var. not assumed & & & & .03 & 1.003 & .3425 \\
\hline
\end{tabular}

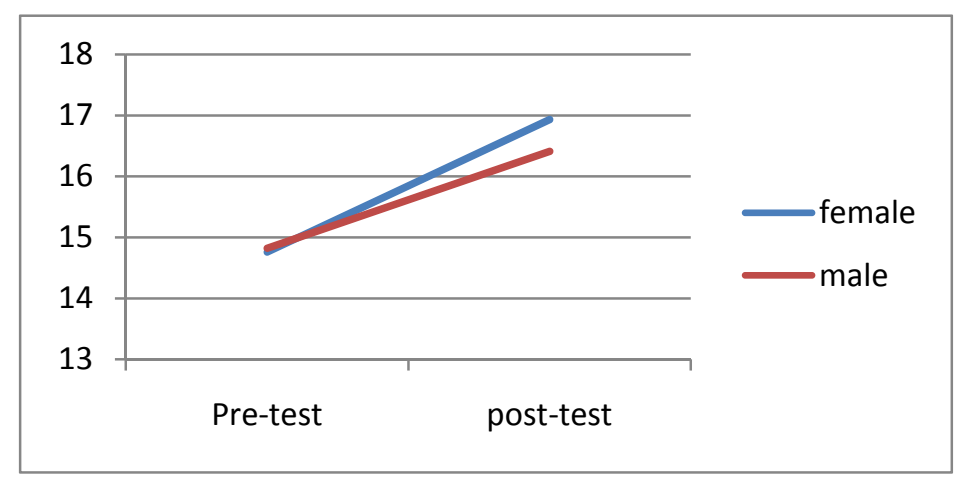

Figure 4. Experimental males and females' participants on the reading comprehension pre and post-test

\subsection{Discussion}

According to the employed statistical analysis, a significant improvement in reading comprehension was observed for the experimental participants after a seven-week of concept mapping instruction. The findings suggest that concept-mapping has positively affected the comprehension of the texts for Iranian EFL learners due to its potential in bringing about better understanding through the language of images, pictures and related boxes and concepts. Moreover, while concept-maps provide teachers and educators perceive the degree of learners' understanding of the text, they help learners organize the texts' content in a very systematized, comprehensible 
way.

In addition, it was also found that female EFL learners benefited from the concept-maps more than their male peers; however, the superiority of females has been documented for some areas and techniques in literature (e.g., Farahani \& Khaghaninejad, 2009). This may imply that females can establish a better relationship with the information stored in visual format than males (Angelo \& Cross, 1993). In fact, they can draw conclusions from the schematic representations easier than male EFL learners.

The results of this study are in line with other studies carried out on the effect of using concept-mapping technique on reading comprehension for ESL learners (e.g., Stice \& Alvarez, 1987). While no study was found dealing with the possible differences of male and female English learners in using concept-maps, this study certified that female Iranian EFL learners were superior than their male peers when concept-map creation and text interpretation is concerned. The superiority of females can potentially be a good topic for further studies; whether it is related to a more active left hemisphere or the fact that females are better strategy-users than males.

\section{Conclusion}

Graphic organizers are recommended as a technique in reading tasks by Chularut and De Backer (2003) because they provide schematic scaffolds that encourage students to extract and represent the meaning of words from texts. Concept mapping as a meta-cognitive and graphic organizer strategy, which emphasizes organization may help students to improve their reading proficiency (Chularut \& De Backer, 2003).

This study was an attempt to scrutinize the efficacy of concept-maps in reading comprehension classes. The obtained results suggested that concept-maps act undeniably positively for reading comprehension classes in Iranian EFL context. It was also revealed that female English learners were superior at employing concept maps for the reading comprehension tasks. This may be related to females' biological privilege which is a bigger and more active right hemisphere (Meissner \& Yun, 2008).

Teacher trainers may plan courses through which young teachers become familiar with how to provide students with concept-maps that best help student improve their reading comprehension. Students should receive explanations about the benefits of using concept-mapping technique to be encouraged to become good readers. This can be done and supported by referring to the results of related empirical enquiries.

The result of this research makes both students and teachers aware of the benefit of using concept-mapping technique. The result of this awareness is that learners would be familiar with their own learning task and it makes them comprehend reading texts better. In the light of the study's findings, it seems reasonable to accommodate the concept mapping in class activities with more attention given to the relationship between reading comprehension and concept maps.

There have been a number of limitations to the present study suggesting that the findings should be interpreted with caution. This study was limited by the shortage of time; the study had to be conducted in a limited time period, so the instructing lasted only seven weeks. Although some development has been observed in all groups, a seven-week period is not enough for a language skill to develop.

\section{References}

Angelo, T., \& A. Cross. (1993). Classroom Assessment Techniques. San Francisco: Jossey-Bass publications. http://dx.doi.org/15.554250/03

Ausible, D. (1968). Meta-cognitive reading strategies increase L2 performance. Language Teaching Journal, 27(7), 112-134.

Berkowitz, S. J. (1986). Effects of instruction in text organization on sixth-grade students' memory for expository reading. Reading Research Quarterly, 21(2), 161-178. http://dx.doi.org/10.2307/747843

Brown, H. D. (2007). Teaching by principles: An interactive approach to language pedagogy. White Plains, NY: Pearson Education. http://dx.doi.org/01361271/18

Burdumy, S. (2006). The role of conscious strategies in second language proficiency. Canadian Modern Language Review, 35, 372-394.

Chamot, A. U. (2005). Learning strategies in foreign language instruction. Foreign Language Annals, 22, 13-24. http://dx.doi.org/10.1111/j.1944-9720.1989.tb03138

Chularut, M., \& De Backer, L. (2003). Insights into second language reading: A cross-linguistic approach. New York, NY: Cambridge University Press. http://dx.doi.org/9781139524841

Day, R. R., \& Bamford, J. (2002). Top ten principles for teaching extensive reading. Reading in a Foreign 
Language, 14, 136-141.

Eskey, D. E. (2005). Reading in a second language. In E. Hinkel (Ed.), Handbook of research on second language teaching and learning. Mahwah, NJ: Lawrence Erlbaum.

Fahim, M., \& Samadian, T. (2011). Sensory style preference of EFL students in Iran. Theory and Practice in Language Studies, 1(6), 644-665. http://dx.doi.org/10.4304/tpls.1.6.644-651

Farahani, A., \& Khaghaninejad, M. S. (2009). A Study of Task-based Approach: The Effects of Task-based Techniques, Gender, and Different Levels of Language Proficiency on Speaking Development. Pazhuhesh-e-Zabanha-ye-Khareji, 49, 23-41.

Grabe, W. (2004). Research on teaching reading. Annual review of applied linguistics, 24, 44-69.

Gul, R. B., \& Boman, J. A. (2006). From Reader to Reading Teacher: Issues and strategies for second language classrooms. New York: Cambridge University Press.

Khodadady, E., \& Khaghaninejad, M. S. (2012). Acquisition of French Polysemous Vocabularies: Schema-based Instruction versus Translation-based Instruction. Porta Linguarum, 17, 29-46. http://dx.doi.org/10/25639/345

Kremer, M. (2005). Problems and issues in the use of concept maps in science assessment. Journal of Research and Scientific Teaching, 33(6), 569-600.

Liu, P. L., Chen, C. J., \& Chang, Y. J. (2010). Effects of a computer-assisted concept mapping learning strategy on EFL college students' English reading comprehension. Computers \& Education, 54, 436-445. http://dx.doi.org/10.1016/j.compedu.2009.08.027

Meissner, F., \& Yun, J. (2008). Revisiting print exposure: Exploring differential links to vocabulary, comprehension and reading rate. Journal of Research in Reading, 31, 273-284. http://dx.doi.org/10/230217624

Miller, R. G. (2006). Unlocking reading comprehension with key science inquiry skills. Scientific Scope, 30(1), 30-33.

Novak, J. D., \& Musonda, D. (1991). A twelve-year longitudinal study of science concept learning. American Educational Research Journal, 28(1), 117-153. http://dx.doi.org/10/12/28/1/117

Nunan, D. (2000). Autonomy in language learning. Plenary presentation at the Columbian Association of Teachers of English.

Oxford, R. L. (2002). Language learning strategies: What every teacher should know. New York: Newbury House.

Rivard, L., \& Yore, L. D. (1992). Review of reading comprehension instruction. Paper presented at the Annual Meeting of New York, 1985-1991.

Snow, C. (2002). Reading for understanding: toward an $R \& D$ program in reading comprehension. RAND Reading Study Group, Santa Monica.

Stice, C. F., \& Alvarez, M. C. (1987). Hierarchical concept mapping in the early grades. Child Education, 64(2), 89-96. http://dx.doi.org/10.1080/00094056.1987.10521513

Zmach, C. C., Sanders, J., Patrick, J. D., Dedeoglu, H., Charbonnet, S., Henkel, M., \& Pringle, R. (2007). Infusing reading into science learning. Educational Leadership, 64(4), 62-66.

\section{Copyrights}

Copyright for this article is retained by the author(s), with first publication rights granted to the journal.

This is an open-access article distributed under the terms and conditions of the Creative Commons Attribution license (http://creativecommons.org/licenses/by/3.0/). 